\title{
A Case of 15-Year Recurrence-free Survival After Microwave Coagulation Therapy for Liver Metastasis from Gastric Cancer
}

\author{
KOICHI KINOSHITA ${ }^{1,2}$, TORU BEPPU ${ }^{1,2}$, TATSUNORI MIYATA ${ }^{1}$, KUNITAKA KURAMOTO $^{1,2}$, \\ YASUSHI YOSHIDA ${ }^{1,2}$, NAOKI UMESAKI ${ }^{1}$, YUKI KITANO ${ }^{1}$, SHIGEKI NAKAGAWA ${ }^{1}$, \\ HIROHISA OKABE ${ }^{1}$, HIDETOSHI NITTA ${ }^{1}$, KATSUNORI IMAI $^{1}$, HIROMITSU HAYASHI ${ }^{1}$, \\ YO-ICHI YAMASHITA ${ }^{1}$, HIROYUKI KOMORI ${ }^{1}$, KEI HORINO ${ }^{1}$, ATSUNOBU MISUMI ${ }^{1}$ and HIDEO BABA ${ }^{1}$ \\ ${ }^{1}$ Department of Gastroenterological Surgery, Graduate School of Life Sciences, \\ Kumamoto University, Kumamoto, Japan; \\ ${ }^{2}$ Department of Surgery, Yamaga City Medical Center, Kumamoto, Japan
}

\begin{abstract}
A 70-year-old man with a growing liver tumor had undergone subtotal gastrectomy with pancreaticoduodenectomy for gastric cancer (T4b PO HO N1, Stage IIIB) 30 months before admission to our hospital. Enhanced computed tomography revealed two hypervascular nodules in segments 4 and 8. After histological diagnosis of small liver metastases from gastric cancer in segment 8 , the patient underwent open microwave coagulation therapy (MCT) for the tumor (diameter: $30 \mathrm{~mm}$ ) in segment 4. MCT was performed by using 1.5-cm and 3-cm monopolar needle electrodes with 22 times of puncture under the condition of $100 \mathrm{~W} \times 60 \mathrm{sec}$. Liver abscess developed at the MCT site; however, it was decreased with percutaneous drainage. The patient is alive, without tumor recurrence even after 15 years since the MCT. This successful case proves that appropriate MCT is a promising treatment for patients with gastric liver metastases.
\end{abstract}

Liver metastases from gastric cancer (LMGC) is a highly malignant disease owing to the frequent and multiple occurrence of liver metastases or accompanying extrahepatic metastases such as peritoneal dissemination and/or lymph node metastasis $(1,2)$. Complete recovery from LMGC with monotherapy alone is difficult; therefore, multidisciplinary treatment consisting of liver resection, systemic chemotherapy, thermal ablation, or transarterial embolization has been attempted (3-9). Despite the advancement in liver

Correspondence to: Hideo Baba, Professor of Department of Gastroenterological Surgery, Graduate School of Life Sciences, Kumamoto University, 1-1-1 Honjo, chuo-Ku, Kumamoto 8608556, Japan. Tel: +81 963735211, Fax: +81 963714378, e-mail: hdobaba@kumamoto-u.ac.jp

Key Words: Liver metastasis from gastric cancer, microwave coagulation therapy. resection technology and modern chemotherapy for LMGC, a 5 -year overall survival (OS) is limited to $0-38 \%$, and there is no report of a 10-year survivor (4). A recent study in China revealed excellent long-term prognosis of LMGC. The 5 -year OS of liver resection (24.4\%) was significantly better compared with that of TACE or radiofrequency ablation (RFA) (12.2\%); however, there is no report of 5-year OS in patients after receiving RFA monotherapy (8). Another study in Japan reported a remarkable 5-year OS of $42.1 \%$ in patients with LMGC treated with surgery alone or with surgery accompanying local ablation therapy; however, this patients' group received $22 \%$ of preoperative and $69 \%$ of postoperative modern chemotherapy (5).

Microwave coagulation therapy (MCT) is one of the thermal ablation therapies for liver tumors and has recently gained much attention (9-11). MCT possesses hyper ablation power to create a larger ablation area without any heat-sink effects unlike RFA (11). Several studies have reported shortand long-term therapeutic results of LMGC; however, a long recurrence-free survival in patients with LMGC has been rarely observed. Herein, we present a 70-year-old man who is alive for over 15 years since MCT for metachronous LMGC.

\section{Case Presentation}

A 70-year-old man was admitted to our hospital because of a growing liver tumor. He was otherwise healthy and presented no symptoms. The patient had undergone subtotal gastrectomy with pancreaticoduodenectomy (T4b P0 H0 N1, Stage IIIB) for advanced gastric cancer 30 months before admission. He was not infected with hepatitis $\mathrm{B}$ or $\mathrm{C}$ virus. Laboratory tests at admission revealed elevated serum carcinoembryonic antigen (CEA) of $2.6 \mathrm{ng} / \mathrm{ml}$ (normal value: $\leq 2.0 \mathrm{ng} / \mathrm{ml}$ ) and CA19-9 of $36.8 \mathrm{U} / \mathrm{ml}$ (normal value: $\leq 37 \mathrm{U} / \mathrm{ml}$ ). He had a linear type of diabetes mellitus. An abdominal ultrasonography disclosed a hyperechoic nodule 

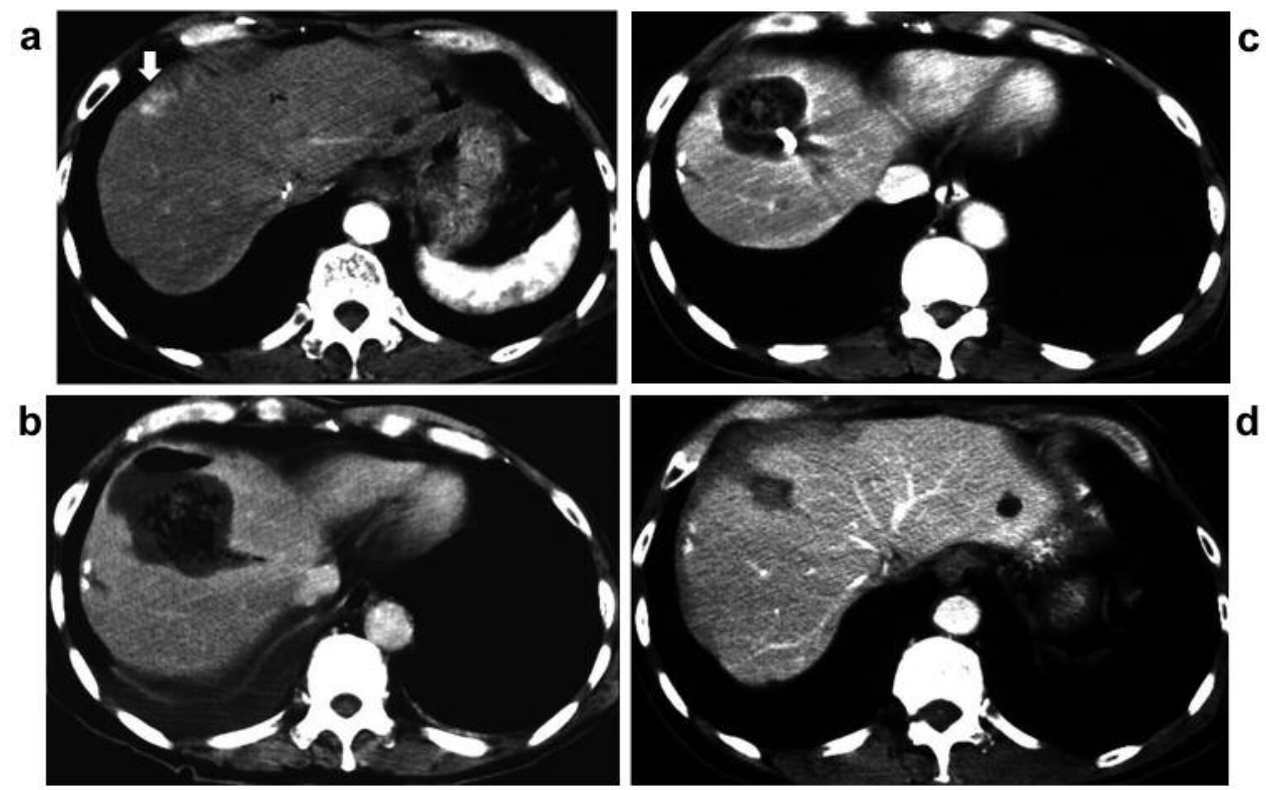

Figure 1. Perioperative enhanced computed tomography (CT). a. Preoperative. b. One week later. c. One month later. d. Six months later. Preoperative CT revealed a well-enhanced tumor (arrow) of $30 \mathrm{~mm}$ diameter in segment 4 (a). One week later, excessive fluid collection with air was detected at the MCT site (b). After 1 month, the liver abscess shrunk with percutaneous drainage (c). Six months later, the liver abscess cavity markedly decreased, and two staples were detected at the enucleation site in segment $8(d)$.

with low echoic halo, i.e., "Bull's eye sign," in the liver segment 4. Enhanced computed tomography (CT) revealed two well-enhanced tumors (diameter, $30 \mathrm{~mm}$ in segment 4 and $8 \mathrm{~mm}$ in segment 8) (Figure 1a). Preoperative diagnosis revealed metachronous LMGC. After informed consent, the patient opted for open MCT rather than liver resection.

An under costal incision was made under general anesthesia. During the operation, massive intra-abdominal adhesion was observed due to prior pancreaticoduodenectomy. After minimal adhesion exfoliation, tumor in segment 8 was enucleated and histologically confirmed as LMGC. We applied MCT for the tumor in segment 4. First, we performed circumferential MCT for the tumor with $0.5 \mathrm{~cm}-1 \mathrm{~cm}$ intervals, followed by MCT of the entire tumor. MCT was performed using monopolar needle electrodes (Alfresa; Osaka, Japan) of lengths $1.5 \mathrm{~cm}$ and $3 \mathrm{~cm}$ for 4 and 18 times, respectively, under the condition of $100 \mathrm{~W} \times 60 \mathrm{sec}$. We applied the overlapping ablation method for complete destruction of the tumor (12). Hemostasis was done for all puncture-site with electric cautery. The operation time was 160 min, and the amount of blood loss was $45 \mathrm{ml}$.

The patient complained of high fever with a high degree of inflammation and was diagnosed with liver abscess at the MCT site by CT on POD 7 (Figure 1b). After percutaneous drainage, the liver abscess gradually decreased and never recurred (Figure 1c and d). After the operation, the serum CEA and CA19-9 levels promptly decreased to the normal range. He was prescribed tegafur-uracil (UFT, $400 \mathrm{mg} /$ day) and Krestin ( $3 \mathrm{~g} /$ day) as an adjuvant therapy for 1 year. The patient is alive, with no incidence of recurrence over more than 15 years since the operation.

\section{Discussion}

We reported herein a case of 15-year recurrence-free survival from multiple metachronous LMGC. Based on the strong hope of patient and his family, MCT was selected instead of liver resection. Laparoscopic MCT was predicted to be difficult owing to extensive intra-abdominal adhesion (13). The main tumor (30 $\mathrm{mm}$ in diameter) was treated with open MCT, and a small tumor was enucleated and subjected to histological examination. Although liver resection is definitely the optimal choice of treatment for LMGC when surgical R0 resection can be achieved (8), the number of patients who have undergone liver resection is limited. In patients who have undergone liver resection $\pm \mathrm{MCT} / \mathrm{RFA}$, independent poor prognostic factors included multiple liver metastases (hazard ratio $(\mathrm{HR})=2.14)$ ) and lymph node metastasis of $\mathrm{N} 2+\mathrm{N} 3(\mathrm{HR}=2.16)(5)$. Our patient exhibited two metachronous LMGC and a N1 lymph node metastasis at the first operation.

Long recurrence-free survival in our patient may have resulted from the following reasons. Firstly, the patient had a liver-only metachronous LMGC with an interval of 30 months. Recurrence-free interval after the initial surgery was 
essential for the patient's survival after treatment for the recurrent tumor (14). Secondly, we selected MCT rather than RFA as the thermal therapy. MCT can provide higher intratumoral temperatures, greater penetration of energy into the cancer tissues, and less heat-sink effects from the surrounding vessels, in contrast bile duct injury occurs more frequently in MCT than in RFA (12). MCT can provide sufficient ablation power regardless of back ground liver (15). Recently, significantly lower ablation-site recurrence rates of MCT were reported compared with those of RFA (6\% vs. 20\%) in patients with colorectal liver metastases (16). Thirdly, postoperative administration of UFT and Krestin may have also contributed to the recurrence-free survival. UFT is a combination of tegafur and uracil, and PSK is an immunostimulant extracted from Coriolus versicolor, which belongs to Basidiomycetes (17). The application of UFT+PSK as an adjuvant chemotherapy has been reported for non-curative resection in patients with advanced gastric cancer (17). A recent randomized phase III study clarified the application of UFT+PSK as an adjuvant chemoimmunotherapy for stage II rectal cancer (18). Fourth, abscess formation after MCT may inhibit local recurrence at the therapeutic site. The patient possessed two other risk factors for liver abscess, i.e., diabetes mellitus and a prior choledocojejunostomy (19). Diabetes mellitus could be controlled by insulin administration. In patients with choledocojejunostomy, intestinal bacteria can easily penetrate the intra-hepatic bile duct. Prior choledocojejunostomy is currently an absolute contraindication for MCT; however, in 1995, this information was not widely known. It has been demonstrated that postoperative complications, especially infectious ones, can postulate early recurrence and poor longterm outcomes in patients undergoing gastric operations (20). Abscess formation is one of the major postoperative complications associated with open MCT. When referring to the local immune response, thermal ablation for liver tumors can enhance tumor-specific T-cell responses (21). Furthermore, severe infection may release heat shock proteins and might suppress the cancer cell progression $(22,23)$.

In conclusion, MCT was able to provide a 15-year recurrence-free survival in a patient with metachronous multiple LMGC despite liver abscess formation after treatment.

\section{Conflicts of Interest}

The Authors declare no conflict of interest.

\section{References}

1 Dicken BJ, Bigam DL, Cass C, Mackey JR, Joy AA and Hamilton SM: Gastric adenocarcinoma: review and considerations for future directions. Ann Surg 241: 27-39, 2005.

2 Boku N: Chemotherapy for metastatic gastric cancer in Japan. Int J Clin Oncol 13: 483-487, 2008.
3 Hwang JE, Kim SH, Jin J, Hong JY, Kim MJ, Jung SH, Shim HJ, Bae WK, Hwang EC, Kim JW, Shin SS, Jeong O, Park YK, Cho SH and Chung IJ: Combination of percutaneous radiofrequency ablation and systemic chemotherapy are effective treatment modalities for metachronous liver metastases from gastric cancer. Clin Exp Metastasis 31: 25-32, 2014.

4 Tao F, Lv J, Wang W and Jin K: Clinical modalities for management of gastric cancer hepatic metastasis. Int J Clin Exp Med 8: 19850-19858, 2015.

5 Oki E, Tokunaga S, Emi Y, Kusumoto T, Yamamoto M, Fukuzawa K, Takahashi I, Ishigami S, Tsuji A, Higashi H, Nakamura T, Saeki H, Shirabe K, Kakeji Y, Sakai K, Baba H, Nishimaki T, Natsugoe S and Maehara Y; Kyushu Study Group of Clinical Cancer: Surgical treatment of liver metastasis of gastric cancer: a retrospective multicenter cohort study (KSCC1302). Gastric Cancer 19: 968-976, 2016.

6 Lee JW, Choi MH, Lee YJ, Ali B, Yoo HM, Song KY and Park $\mathrm{CH}$ : Radiofrequency ablation for liver metastases in patients with gastric cancer as an alternative to hepatic resection. BMC Cancer 17: 185, 2017.

7 Guner A, Son T, Cho I, Kwon IG, An JY, Kim HI, Cheong JH, Noh $\mathrm{SH}$ and Hyung WJ: Liver-directed treatments for liver metastasis from gastric adenocarcinoma: comparison between liver resection and radiofrequency ablation. Gastric Cancer 19: 951-960, 2016.

8 Li J, Zhang K, Gao Y, Xi H, Cui J, Liang W, Cai A, Wei B and Chen L: Evaluation of hepatectomy and palliative local treatments for gastric cancer patients with liver metastases: a propensity score matching analysis. Oncotarget 8: 61861-61875, 2017.

9 Caivano D, Valeriani M, Russo I, Bonome P, DE Matteis S, Minniti G and Osti MF: Stereotactic body radiation therapy in primary and metastatic liver disease. Anticancer Res 37: 70057010, 2017.

10 Bhardwaj N, Strickland AD, Ahmad F, Dennison AR and Lloyd DM: Liver ablation techniques: a review. Surg Endosc 24: 254265, 2010.

11 Rocha FG and D'Angelica M: Treatment of liver colorectal metastases: role of laparoscopy, radiofrequency ablation, and microwave coagulation. J Surg Oncol 102: 968-974, 2010.

$12 \mathrm{Yu} \mathrm{H}$ and Burke CT: Comparison of percutaneous ablation technologies in the treatment of malignant liver tumors. Semin Intervent Radiol 31: 129-137, 2014.

13 Beppu T, Ishiko T, Masuda T, Hayashi H, Komori H, Okabe H, Mizumoto T, Sugiyama S, Doi K, Takamori H, Hirota M and Baba H: Endoscopic local ablation therapy (ELAT) for hepatocellular carcinoma. Thermal Med 23: 63-70, 2007.

14 Fong Y, Fortner J, Sun RL, Brennan MF and Blumgart LH: Clinical score for predicting recurrence after hepatic resection for metastatic colorectal cancer: analysis of 1001 consecutive cases. Ann Surg 230: 309-318, 1999.

15 Wang LG, Jiang WJ, Fan WJ, Zheng YB, Song XP, Liu S, Sun BL and Wang T: Microwave ablation: The differences between biliary cirrhosis and normal porcine liver using a cooled-tip electrode. Anticancer Res 36: 1221-1226, 2016.

16 Correa-Gallego C, Fong Y, Gonen M, D'Angelica MI, Allen PJ, DeMatteo RP, Jarnagin WR and Kingham TP: A retrospective comparison of microwave ablation $v s$. radiofrequency ablation for colorectal cancer hepatic metastases. Ann Surg Oncol 21: 42784283, 2014.

17 Yoshinaga K, Saeki H, Oki E, Morita M, Ikeda T, Sugimachi K, Yamashita Y, Ikegami T, Uchiyama H, Yoshizumi T, Soejima Y, 
Kawanaka H, Mimori K, Watanabe $\mathrm{M}$ and Maehara $\mathrm{Y}$ : Prognostic markers for immunochemotherapy using tegafur uracil (UFT) and protein-bound polysaccharide K (PSK). Fukuoka Igaku Zasshi 104: 549-558, 2013.

18 Okuno K, Aoyama T, Oba K, Yokoyama N, Matsuhashi N, Kunieda K, Nishimura Y, Akamatsu H, Kobatake T, Morita S, Yoshikawa T, Sakamoto J and Saji S: Randomized phase III trial comparing surgery alone to UFT + PSK for stage II rectal cancer (JFMC38 trial). Cancer Chemother Pharmacol, 2017. doi: 10.1007/s00280-017-3466-7. [Epub ahead of print]

19 Shimada S, Hirota M, Beppu T, Matsuda T, Hayashi N, Tashima $\mathrm{S}$, Takai E, Yamaguchi K, Inoue $\mathrm{K}$ and Ogawa M: Complications and management of microwave coagulation therapy for primary and metastatic liver tumors. Surg Today 11: 1130-1137, 1998.

20 Tokunaga M, Tanizawa Y, Bando E, Kawamura T and Terashima M: Poor survival rate in patients with postoperative intraabdominal infectious complications following curative gastrectomy for gastric cancer. Ann Surg Oncol 20: 1575-1583, 2013.
21 Zerbini A, Pilli M, Penna A, Pelosi G, Schianchi C, Molinari A, Schivazappa S, Zibera C, Fagnoni FF, Ferrari C and Missale G: Radiofrequency thermal ablation of hepatocellular carcinoma liver nodules can activate and enhance tumor-specific T-cell responses. Cancer Res 66: 1139-1146, 2006.

22 Calderwood SK, Murshid A and Gong J: Heat shock proteins: conditional mediators of inflammation in tumor immunity. Front Immunol 3: 75, 2012.

23 Liu YC, Zou XB, Chai YF and Yao YM: Macrophage polarization in inflammatory diseases. Int J Biol Sci 10: 520529, 2014.

Received December 11, 2017

Revised December 26, 2017

Accepted December 29, 2017 